the density calculated from the modern (Meyer's revised) model $^{2}$ of the unit cell of native cellulose.

Using Meyer's dimensions for the unit cell and a molecular weight of 324.16 for the cellobiose residue $\left(\mathrm{C}_{12} \mathrm{H}_{20} \mathrm{O}_{10}\right)$ a theoretical density of $1.582 \mathrm{~g} / \mathrm{cc}$ has been calculated by this writer. In the construction of the unit-cell model on which these calculations are based, an approximate density is required to supplement the $x$-ray diffraction data, as a contribution to the general plan according to which the $\mathrm{x}$-ray data are to be interpreted. However, the dimensions which are ultimately assigned to the unit crystal, and the density deduced therefrom, are clearly not functions of a prior density. The $\mathrm{x}$-ray data are the same for celluloses of different origins.

While frequent need arises for the "true" or "crystal" density of cellulose in investigations on cellulosic materials and fibers, no notice appears to have been taken in the literature of the excellent agreement between Stamm and Hansen's value and the theoretical value. Because of this agreement, Stamm and Hansen's results appear as an experimental verification of the Meyer model. On the other hand, the unusually high value reported by Stamm and Hansen finds justification in the theoretical model. The most persistent, systematic, experimental error to be expected in density measurements on cellulose is that arising from void spaces. The low values previously reported differ from the theoretical value in the direction which would be expected if inadequate correction is made for porosity. All of these considerations greatly enhance the reliability of $1.582-1.585 \mathrm{~g} / \mathrm{cc}$ as the density of native cellulose in the continuous crystal lattice.

${ }^{1}$ A. J. Stamm and L. A. Hansen, J. Phys. Chem, 41, 1007 (1937). 2 Meyer and Misch, Helv. Chim. Acta 20, 232 (1937).

\section{One-Sided Polarization of Ions in Vapor Molecules}

\author{
Kasimir FaJANS \\ Department of Chemistry, University of Michigan, Ann Arbor, Michigan \\ March 12, 1941
}

$\mathrm{T}$ $\mathrm{HE}$ tightening of anions and loosening of cations was demonstrated recently ${ }^{1}$ in an especially simple way by the deviations from additivity of lattice distances and volumes of ionic crystalline substances of high symmetry. The occurrence of these volume effects also in the case of a one-sided interaction of ions has been shown indirectly by considering the individual behavior of the apparent volume of dissolved strong electrolytes. ${ }^{1} \mathrm{~A}$ direct proof for the one-sided effects can be found in the gradation of interionic distances in the vapor molecules of $\mathrm{alkali}^{2}$ and thallous ${ }^{3}$ chlorides, bromides and iodides, measured by the electron diffraction method. According to the authors, the values have an accuracy of between \pm 0.01 and $\pm 0.04 \mathrm{~A}$, so that only considerable deviation from additivity can be interpreted with certainty as due to these polarization effects.

In vaporized sodium and potassium halides, the diminution of the size of the anion can be expected to be stronger

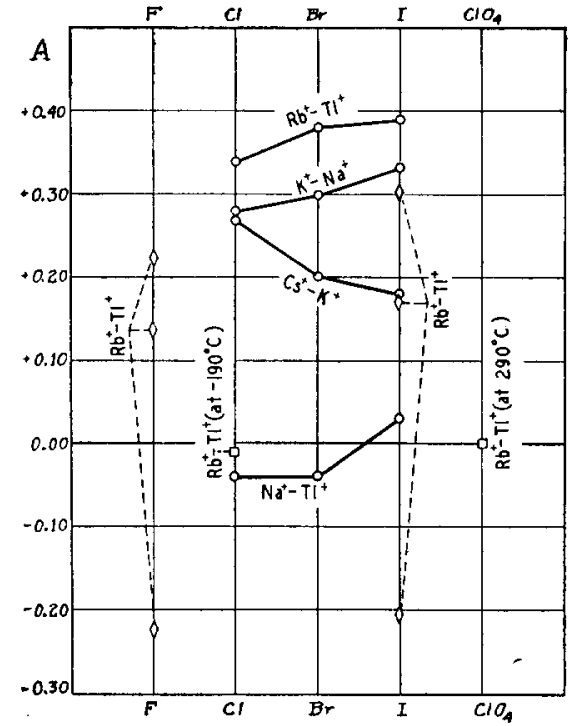

FIG. 1. Comparison of interionic distances in vapor molecules $\left(O^{\prime}\right)$ cubic crystals ( $\square)$ and in rhombic T1F and T1I with cubic RbF and $\mathrm{RbI}(\diamond)$.

than the increase of the size of the cation. Since the polarizability increases from $\mathrm{Cl}^{-}$to $\mathrm{I}^{-}$and the polarizing field of $\mathrm{Na}^{+}$is stronger than that of $\mathrm{K}^{+}$one understands that the difference in the interionic distances between $\mathrm{K}^{+}$and $\mathrm{Na}^{+}$increases from $\mathrm{Cl}^{-}(0.28 \mathrm{~A})$ to $\mathrm{I}^{-}(0.33$, see Fig. 1). On the other hand the difference between $\mathrm{Cs}^{+}$and $\mathrm{K}^{+}$ decreases from $\mathrm{Cl}^{-}(0.27)$ to $\mathrm{I}^{-}(0.18)$ which indicates that at least in the vapor molecules of the $\mathrm{CsCl}$ the loosening of $\mathrm{Cs}^{+}$by $\mathrm{Cl}^{-}$is stronger than the opposite effect.

In their high temperature cubic form $\mathrm{TlClO}_{4}$ and $\mathrm{RbClO}_{4}$ have $\mathrm{a}$ unit cell of identical edge length $\left(7.7_{0} \mathrm{~A}\right)$, which confirms V. M. Goldschmidt's conclusion that in crystals in which the polarizing effects are weak, $\mathrm{Tl}^{+}$and $\mathrm{Rb}^{+}$are of equal size. The outer electronic system of $\mathrm{Tl}^{+}$ consists of an 18-electron shell with two extra electrons. Cations without a rare gas structure exhibit, in general, stronger polarizing effects on anions than those of rare gas type. On the other hand, the polarizability of $\mathrm{Tl}^{+}\left(R_{\infty}=9.5\right.$ cc) is larger even than that of $\mathrm{Cs}^{+}(6.5 \mathrm{cc})$. Thus, the interionic distances of $\mathrm{TICl}\left(3.24_{9}\right)$ and $\mathrm{RbCl}\left(3.24_{1}\right)$ at $-190^{\circ} \mathrm{C}$, where both have the $\mathrm{CsCl}$ structure, ${ }^{5}$ show that here the stronger tightening effect of $\mathrm{Tl}^{+}$on $\mathrm{Cl}^{-}$is just balanced by the stronger loosening of $\mathrm{Tl}^{+}$.

However, as a result of the one-sided action within the vaporized molecules, the interionic distance in $\mathrm{TlCl}$ (2.55) is much smaller than in $\mathrm{RbCl}(2.89)$ and only a little larger than in $\mathrm{NaCl}$ (2.51); in TII the distance (2.87) is even smaller than in NaI (2.90).

The short distances within the thallous halide molecules show a strong deformation of ions and confirm the conclusion, ${ }^{6}$ based on absorption spectra, that their structure is nearer to covalent than to ionic. This explains the fact that $\mathrm{TlCl}$ is distinctly less dissociated ${ }^{7}$ in aqueous solution than alkali halides, as well as its low boiling point $\left(806^{\circ} \mathrm{C}\right.$; that of $\mathrm{RbCl}$ is $1383^{\circ}$ ). 
In connection with these one-sided polarization effects, it is of interest that in both the rhombic TIF and TII, there different interionic distances occur. In TIF each ion is connected with three pairs of oppositely charged ions at the distances $2.59,2.75$ and $3.04 \mathrm{~A} .^{8}$ In T1I there is one neighbor at the distance 3.36 , four are at 3.49 and two at $3.87 \mathrm{~A}^{9}$

The smallest of the three distances lies between those of the corresponding solid Na- and K-salts. The largest is nearest to that in $\mathrm{CsF}(3.00)$ and CsI (3.95), respectively. One can assume that the longest distance in both $\mathrm{TlF}$ and TII is due to the loosening effect by the anions interpenetrating the $\mathrm{Tl}^{+}$and is influenced especially by the two extra electrons in the outer shell of $\mathrm{TI}^{+}$, which contribute to its high polarizability. The smallest distance must be due to the tightening of the anions by $\mathrm{Tl}^{+}$.

1 K. Fajans, J. Chem. Phys. 9, 281 (1941),

2 L. R. Maxwell, S. B. Hendricks and V. M. Mosley, Phys. Rev, 52 968 (1937). The value for RbI seems to be too low by about $0.1 \mathrm{~A}$.

3 W. Grether, Ann. d. Physik 26, 1 (1936).

4 H. Grackeren and L. Harang, Zeits f. Krist. 75, 538 (1930).

$5 \mathrm{G}$. Wagner and L. Lippert, Zeits. f. physik. Chemie B33, 297 (1936).

6. K. Butkow, Zeits. f. Physik 58, 232 (1929).

7 L. Onsager, Physik. Zeits. 28, 277 (1927).

8 J. A. A. Ketelaar, Zeits. f. Krist. 92, 30 (1935).

${ }^{9}$ L. Helmholz, Zeits. f. Krist. 95, 129 (1936).

\section{Thermal Transitions in Ammonium and Silver Trihydrogen Paraperiodates*}

C. C. Stephenson

Research Laboralory of Physical Chemistry, Massachusetts Instilute of Technology, Cambridge, Massachusetts

February 27, 1941

$A^{\top}$ $\mathrm{T}$ low temperatures the salts $\mathrm{KH}_{2} \mathrm{PO}_{4}$ and $\mathrm{KH}_{2} \mathrm{AsO}_{4}$ become spontaneously polarized; an entropy change ${ }^{1}$ and corresponding thermal effect are associated with the transition from the polarized to the unpolarized state. According to the theory of the transition as given by Slater, ${ }^{2}$ the unusual properties of these salts are due to the various arrangements of the hydrogen ions which form hydrogen bonds joining the phosphate or arsenate groups to each other. Insofar as the hydrogen bonds are concerned, the structure ${ }^{3}$ of $\left(\mathrm{NH}_{4}\right)_{2} \mathrm{H}_{3} \mathrm{IO}_{6}$ is similar to that of $\mathrm{KH}_{2} \mathrm{PO}_{4}$ except that the octahedral $\mathrm{IO}_{6}$ ion is linked to neighboring paraperiodate groups by six hydrogen bonds while the tetrahedral phosphate group has only four hydrogen bonds. In both cases the hydrogen bonds are unsymmetrically arranged around the central group and a preferred orientation of the hydrogens at low temperatures is possible. This configuration of lowest energy is the polarized form of $\mathrm{KH}_{2} \mathrm{PO}_{4}$.

In view of these similarities, one would expect a transition in $\left(\mathrm{NH}_{4}\right)_{2} \mathrm{H}_{3} \mathrm{IO}_{6}$ similar to the transition in $\mathrm{KH}_{2} \mathrm{PO}_{4}$ but with a somewhat higher entropy change due to the larger number of hydrogen bonds.
Preliminary measurements were made in a simple coolingcurve apparatus and a maximum was found in the heat capacity of the ammonium trihydrogen paraperiodate at $254^{\circ} \mathrm{K}$. This transition is presumably caused by the hydrogen bonds, although there is a possibility that the ammonium groups, which cause similar transitions in many ammonium salts, are responsible. $\mathrm{Ag}_{2} \mathrm{H}_{3} \mathrm{IO}_{6}$, which is isomorphous with the ammonium salt, has a transition with a maximum in the heat capacity at about $227^{\circ} \mathrm{K}$. The reorientation of the hydrogen bonds is the only plausible explanation for this transition, and the presence of the transition is additional evidence that the formula for this salt is not $\mathrm{Ag}_{4} \mathrm{I}_{2} \mathrm{O}_{9} \cdot 3 \mathrm{H}_{2} \mathrm{O}$ as it is frequently written. The corresponding sodium salt, $\mathrm{Na}_{2} \mathrm{H}_{3} \mathrm{IO}_{6}$, has a different external crystallographic symmetry and exhibits no transition between liquid air and room temperature.

The silver and ammonium salts would have zero entropy at the absolute zero, because an ordered arrangement of the hydrogen bonds occurs below the transition temperatures. Without further information concerning the positions of the hydrogens in the sodium salt, it is impossible to say whether or not an entropy calculation from low temperature heat capacity data would be correct. A residual entropy associated with a random orientation of the hydrogen bonds may persist to the lowest attainable temperature, as in the case of ice, ${ }^{4}$ or an ordered arrangement of zero entropy may already exist at room temperature.

The presence of the transitions in the ammonium and silver salts leaves little doubt that the hydrogen bonds are resporsible. On the basis of the hydrogen bond theory, the total entropy change associated with the transitions in the trihydrogen paraperiodates is $R \log 5 / 2$ in contrast to $R \log 3 / 2$ for the dihydrogen phosphates. Further studies are planned to test this prediction, and to investigate the spontaneous polarization and anomalous piezoelectric effect which are also predicted.

* Contribution No. 474 from the Research Laboratory of Physical Chemistry, Massachusetts Institute of Technology.

1 C. C. Stephenson and J. G. Hooley, Phys. Rev. 56, 121 (1939); C. C. Stephenson and A. C. Zettlemoyer, to be published.

2 J. C. Slater, J. Chem. Phys. 9, 16 (1941).

${ }^{3} \mathrm{~L}$. Helmhoiz, J. Am. Chem. Soc. 59, 2036 (1937).

${ }^{4}$ L. Pauling, J. Am. Chem. Soc. 57, 2680 (1935).

\section{Erratum: The Temperature Coefficient of the Conductance of Potassium Chloride in $\mathrm{H}_{2} \mathrm{O}-\mathrm{D}_{2} \mathrm{O}$ Mixtures}

VICTOR K. LAMER AND FREDERICK C. NACHOD

Department of Chemistry, Columbia Universily, New York, New York (J. Chem. Phys, 9, 265 (1941))

In this article, Figs. 1 and 2 were interchanged. Figure 1 should be Fig. 2, with the legend denoted as Fig. 2. Figure 2 should be Fig. 1 with the legend denoted as Fig. 1. 